\title{
Análisis de la producción científica mundial por regiones
}

\author{
Por Grupo Scimago
}

\begin{abstract}
Grupo Scimago. "Análisis de la producción científica mundial por regiones”. En: El profesional de la información, 2007, marzo-abril, v. 16, n. 2, pp. 158-159.

DOI: 10.3145/epi.2007.mar.11
\end{abstract}

CON ESTA ENTREGA de nuestra ya habitual cita en EPI se inaugura esta nueva sección de la revista sobre indicadores. Su contenido estará centrado en los temas métricos de la información en su sentido más amplio. El creciente interés por estos temas en el mundo profesional y científico, tanto en nuestro campo como en otros, hace necesaria, en nuestra opinión, la regularización de estos contenidos en EPI a través de la sección recién creada. Por este motivo, saludamos con entusiasmo la idea y le deseamos el mayor de los éxitos. En nuestra primera colaboración en la recién creada sección hacemos un breve análisis de la distribución regional de la ciencia mundial.

El número de publicaciones científicas generadas por un país puede ser utilizado como un indicador para medir su desarrollo científico y compararlo con el de otros. Gálvez, et al. (2000), en un estudio realizado a partir de las revistas contenidas en el Science citation index en el periodo 1991-1998, se puso de manifiesto que el $85 \%$ de los trabajos científicos procedían de tres regiones: Europa occidental, América del norte y la región Asiática. Además por primera vez en la historia, la región de Europa del oeste superaba a partir del año 1995 a la producción de América del norte. No obstante, en términos de porcentaje, la región de América latina, era la que obtenía una mayor tasa de crecimiento. Leydesdorff (en prensa), basándose también en el SCI, pero en este caso sólo en el año 2004, manifiesta que durante la última década se han producido grandes cambios en las regiones productoras de publicaciones científicas: China está experimentado un crecimiento exponencial en cuanto a su número de publicaciones y Estados Unidos se está viendo superada por una Unión Europea en expansión.

En este trabajo mostramos la situación actual de la producción científica mundial por regiones, a partir de la información obtenida del Web of knowledge, en concreto de las bases de datos del Science citation index-expandex (SCI-E), Social science citation index (SSCI) y Arts \& humanities citation index (A\&HCI), en el periodo 1999-2004. Las regiones del mundo y los países que las componen son los mismos que los utilizados por Gálvez, et al. La única diferencia es que, por la
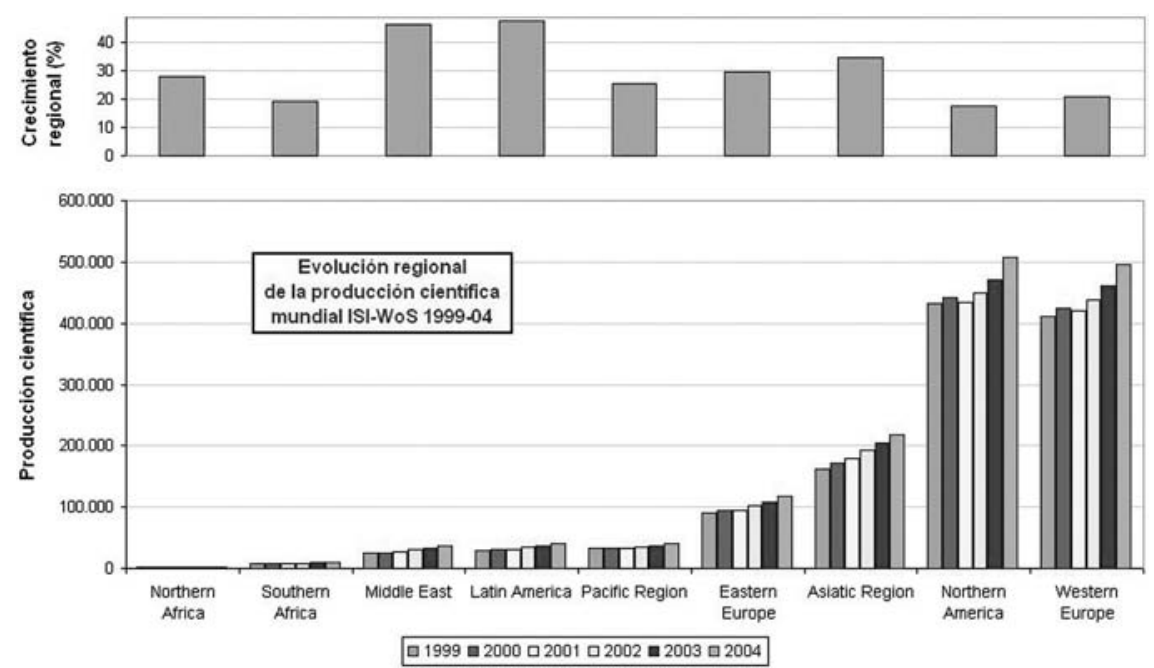

fecha de su trabajo, cuando hablan de la región de Europa del oeste hacen referencia a la Europa de los 15 , mientras que nosotros nos reseñaremos a la Europa de los 25.

El gráfico siguiente muestra la tasa de variación (\%) de las distintas regiones representadas y su producción anual desde el año 1999 hasta el 2004.

$\mathrm{Al}$ igual que Galvez et al., comprobamos que la mayor producción científica se centra en tres regiones: Europa occidental, América del norte y la región Asiática. No obstante y a diferencia del estudio anterior, Europa del oeste no supera en producción científica a América del norte, aunque en el 2004 sus producciones son muy similares. Está diferencia entre un trabajo y otro se debe a que, como hemos dicho anteriormente, nosotros incluimos además la producción científica en ciencias sociales y humanidades. 
"El incremento del $20 \%$ anual de China no tiene precedente. En muy poco años podría convertirse en el segundo productor de publicaciones científicas"

$\mathrm{Al}$ analizar el gráfico anterior, llama la atención las diferencias tan significativas que se producen en la distribución de la producción mundial entre regiones. Norteamérica parece haber llegado a su nivel de saturación en cuanto a su capacidad de crecimiento. Sin embargo en la Europa del oeste, se aprecia un incremento sostenido que con el paso a la Europa de los 25, presenta un gran potencial de aumento debido a las bajas tasas de producción existentes aún en algunos países recién
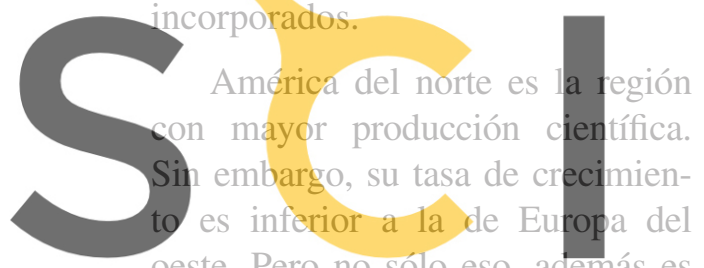

a menor de todas las reoiones que

Register far free at httpsk fww s6ipe

producción la tiene América latina

Esto se debe fundamentalmente a la aportación de Brasil, que en términos relativos está creciendo mucho más que cualquier otro país de la región, compensando porcentajes muy bajos en este momento como los de Argentina o Venezuela. Es muy significativo también el ritmo de desarrollo de la región Asiática. Pero aquí no vamos a descubrir la pólvora. El

\section{El profesional de la información}

está abierto a todos los bibliotecarios, documentalistas y otros profesionales de la información, así como a las empresas y organizaciones del sector para que puedan exponer sus noticias, productos, servicios, experiencias y opiniones.

Dirigir todas las colaboraciones para publicar a:

El profesional de la información

Apartado 32.280

\section{Barcelono \\ epi@elprofesionaldelainformacion.com}

motor de China está detrás. Este país

Bibliografía
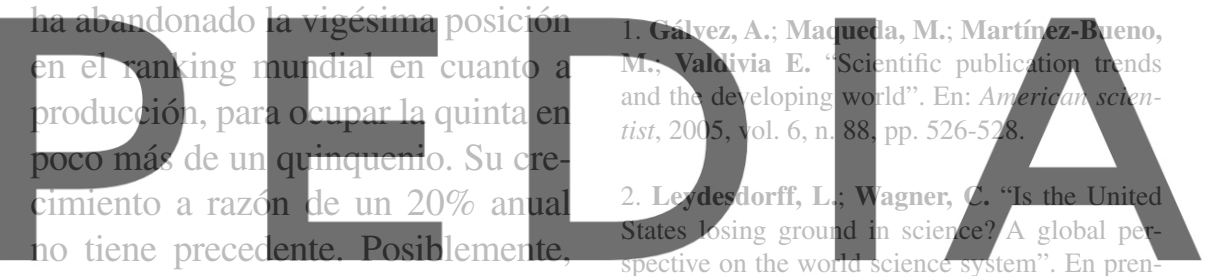

en muy pocos años, se convierta en

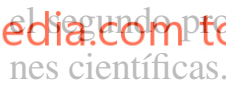

Pero no todo es producción y cifras elevadas. Si planteamos la relación cantidad versus calidad, es decir, si enfrentamos producción científica con las citas recibidas, los resultados pueden ser muy distintos a los que aquí estamos observando. Este aspecto lo estudiaremos en el próximo número de El profesional de la información.
Mova-Anegón, Fr de (dir): Chinchilla-Rodríguez, Z. (coord.). Indicadores bibliométricos de la actividad científica española - 2004. Madrid: Fundación Española para la Ciencia y la Tecnología (FECyT), 2005.

Grupo Scimago (Imago scientiae o visualización de la ciencia) scimago@ugr.es

http://www.atlasofscience.net

\section{Leer EPI es como asistir a un curso de formación continua pero con el horario acomodado a tus necesidades.}

